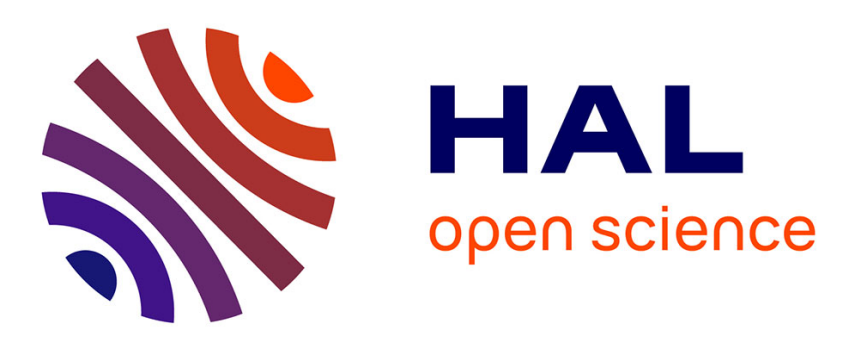

\title{
Are judgments for action verbs and point-light human actions equivalent?
}

Christel Bidet-Ildei, Lucette Toussaint

\section{To cite this version:}

Christel Bidet-Ildei, Lucette Toussaint. Are judgments for action verbs and point-light human actions equivalent?. Cognitive Processing, 2015, 16 (1), pp.57-67. 10.1007/s10339-014-0634-0 . hal01118999

\section{HAL Id: hal-01118999 \\ https://hal.science/hal-01118999}

Submitted on 7 Jan 2019

HAL is a multi-disciplinary open access archive for the deposit and dissemination of scientific research documents, whether they are published or not. The documents may come from teaching and research institutions in France or abroad, or from public or private research centers.
L'archive ouverte pluridisciplinaire HAL, est destinée au dépôt et à la diffusion de documents scientifiques de niveau recherche, publiés ou non, émanant des établissements d'enseignement et de recherche français ou étrangers, des laboratoires publics ou privés. 
Are judgments for action verbs and point-light human actions equivalent?

Bidet-Ildei Christel \& Toussaint Lucette

Centre de recherches sur la cognition et l'apprentissage, UMR 7295-CNRS,

Université de Poitiers, France

Corresponding author: Christel Bidet-Ildei

Mailing Address:

Christel Bidet-Ildei $(\mathrm{PhD})$

CeRCA/MSHS, Bâtiment A5

5, rue Théodore Lefebvre

TSA 21103

86073 Poitiers cedex 9

Tel.: 33 (0)5 49454697

Fax: 33 (0)5 49454616

Email: christel.bidet@univ-poitiers.fr 


\section{ABSTRACT}

The aim of the present study was to examine whether the ability to judge action words and the ability to judge human actions share common mechanisms. With this purpose in mind, we proposed both a lexical and an action decision task to twenty-four healthy participants. For both tasks, the participants had to judge whether the stimulus that was presented (a letter string or a point-light sequence) was valid or not (i.e., a word vs. a pseudo-word, an action vs. a pseudo-action). The data analysis showed that the action decision task has common characteristics with the lexical decision task. As for verbal material, judgements of pseudoactions were slower than judgements for actions. Moreover, we demonstrated that the ability to judge an action verb was positively correlated with the ability to judge a point-light human action whereas no significant correlation appeared between nouns and point-light judgements abilities. This dissociation supports the argument that the judgement of action words and the judgement of human actions share a common but specific basis through the involvement of motor representations.

Key words: action words, judgement ability, point-light human actions, sensorimotor representations. 


\section{INTRODUCTION}

"Embodied theory" suggests that high-level cognitive processes are based on sensorimotor experience (Barsalou, 1999; Wilson, 2002). In this context, a lot of works have shown that sensorimotor processes are involved during tasks implying semantic representations and/or processing (for a review, see Andres, Olivier, \& Badets, 2008; Coello \& Bidet-Ildei, 2012; Fischer \& Zwaan, 2008). In the present study, we are particularly interested in the importance of motor processes in language understanding. In this framework, several studies have shown that language processing can influence ongoing motor performance (Boulenger et al., 2006; Gentilucci, 2003; Glover \& Dixon, 2002; Nazir et al., 2008). For example, processing action words interferes with the production of reaching movements when the two tasks occur at the same time (Boulenger et al., 2006). Interestingly, it has been suggested that these effects are not the consequence of the conscious processing of the word (Boulenger et al. 2008). Indeed, presenting an action verb to a participant at a subliminal level during the preparation of a reaching movement was found to affect the kinematic parameters of the motor response. These findings demonstrate that action words can automatically influence motor processes even when the words are processed out of the consciousness. Interestingly, a recent study showed automatic bidirectional relationships between the production of an action word and the production of a human action (Liepelt, Dolk, \& Prinz, 2012). When people have to open or close their hand, their response times increased when an incongruent action word was previously presented. In the same manner, when people have to pronounce action words, their response times were higher when an incongruent action was previously presented. This bidirectional effect was also sustained by cortical recordings in motor and language areas (Aravena et al., 2010; Ibanez et al., 2013). Actually, Ibanez et al. (2013) have shown that language areas activity is affected when a 
current action is realized during the processing of action-related sentence and reciprocally, sentence processing affects motor cortical activity in premotor and primary motor cortex.

Studies of cerebral activations have equally provided arguments in favour of cross-talk between language and motor processes. Similar regions that include motor areas are activated when humans have to produce actions or have to pronounce action words (for a review, see Pulvermüller, 2013). However, this cerebral network could encompass a large corticosubcortical network which is not restricted to somatotopically defined brain areas (Cardona et al., 2013; Ibanez et al., 2013). Additional evidence comes from clinical reports that have shown a close link between movement disorders (e.g., Parkinson's disease, Huntington's disease, progressive supranuclear palsy) or lesions in the motor brain areas and language impairments when processing action words (Bak, O'Donovan, Xuereb, Boniface, \& Hodges, 2001; Cardona et al., 2013; Cotelli et al., 2006; Peran, Demonet, Pernet, \& Cardebat, 2004; Peran et al., 2003). For example, when patients suffering from Parkinson's disease are offdopa (i.e., without dopaminergic treatment), the presentation of a verb as a prime does not facilitate the subsequent judgment of an identical verb, but this facilitation occurs in healthy controls and on-dopa patients (Boulenger et al., 2008). This effect confirmed that the integrity of the brain motor system is essential for action word processing (see also Cardona et al., 2013).

In the present experiment, contrary to previous studies that investigated the influence of action words processing on action production and reciprocally, we mainly focused on the hypothesis that both tasks share common sensorimotor representations and are based on similar mechanisms. Some studies have effectively suggested that understanding action words could be related to motor processing as well as to other functions that request motor representation, such as the visual judgments of human action (Aziz-Zadeh, Wilson, Rizzolatti, \& Iacoboni, 2006). In this context, Springer and Prinz (2010) showed that semantic 
processing affects the ability to predict whether a static image shows a coherent continuation of a human action sequence that is partially occluded. Given that the ability to predict the result of a human action is linked with action simulation (Chary et al., 2004; Graf et al., 2007; Martel, Bidet-Ildei, \& Coello, 2011), this effect suggests the existence of a relationship between action semantics and sensorimotor representations (see also Springer, Huttenlocher, \& Prinz, 2012). In the same vein, Bidet-Ildei et al. (2011) clearly showed that the perceptual judgement of a human action can be facilitated by prior exposure to an action-related word. When participants had to discriminate a point-light running movement embedded in a mask, they were faster when they were previously exposed to the verb "run" in comparison with non-congruent action verb (i.e., throw) or neutral verb (i.e., think). Implication of motor representations is also sustained at a neurophysiological level by demonstrating that the superior temporal sulcus (STS), a cerebral area that is specifically activated during the observation of human movements, is also activated during the generation of sentences that implicate action verbs (Khader, Jost, Mertens, Bien, \& Rosler, 2010).

Overall, the previous studies suggest that action-related language and action observation share common motor representations and are based on similar mechanisms. However, no study has thoroughly investigated this assumption, and this was the aim of the present work. More specifically, we aimed to test whether action word understanding and visual judgements of human actions share common mechanisms. For this purpose, the present study on healthy participants used two independent tasks, one implying the recognition of words (i.e., lexical decision task) and one implying the recognition of actions (i.e., action decision task). In the lexical decision task, the participants had to judge whether a letter string represented a valid French word. In the action decision task, the participants had to decide whether a point-light sequence represented a valid human action. Consequently, in both tasks, participants have to judge whether a set of signals (i.e., letters in the lexical decision tasks and 
point-light in the action decision task) represents or not something known (i.e., a word in the lexical decision task and an action in the action decision task). Therefore, from a methodological point of view both tasks are very similar. If the action decision task shares common mechanisms with the lexical decision task, we should observe common characteristics on the processing of the two tasks. Specifically, both tasks should be perturbed (i.e., higher response time and/or less accuracy) by pseudo-material. Note that although the effect of pseudo-words is known in the language literature, no study has yet examined the effect of pseudo-action judgements. Moreover, correlational analyses between the lexical decision task and the action decision task should highlight the specific relationship between action words understanding and action observation. Specifically, we predict that the ability to judge action verbs should be related to the ability to judge point-light actions, whereas the ability to judge nouns (i.e., non-action words) should be unrelated to the ability to judge point-light actions.

\section{METHOD}

\section{Participants}

Twenty four French-speaking 18-25 year old (mean age $(M)=20.1$ years, standard deviation $(\mathrm{SD})=2.2$ years $)$ university students (16 females, 18 right-handed) participated in the experiment for course credit. Each participant was healthy, had normal or corrected-to-normal vision and no history of motor, perceptual or neurological disorders. The experiment was performed in accordance with the ethical standards established by the Declaration of Helsinki. All participants provided their written, informed consent prior to their inclusion in the experiment. Before testing, the participants were naïve to the aims of the experiment. 


\section{Material and task}

The participants were required to complete both a lexical decision task and an action decision task.

In the lexical decision task, the participants had to decide whether a string of letters was a French word or not. The verbal material (see Table 1 and Appendix 1) consisted of thirtyeight French words (19 nouns and 19 verbs) that were selected from the French lexical database Lexique 2.0 (New, Pallier, Ferrand, \& Matos, 2001). All action verbs were in the infinitive form and represented human actions (e.g., write, smile), but the nouns referred to objects without specific motor associations (e.g., sword, building). The action verbs and nouns were matched for the relevant lexical variables, including word frequency, number of letters and syllables (see Table 1 for results of the different comparisons). The two linguistic word categories (i.e., nouns and verbs) have been selected to major the motor-relatedness difference while maintaining the imageability of words. Imageability was assessed by participants at the end of the experiment and revealed no difference between nouns and verbs (see table 1). Motor relatedness was assessed by 37 participants who did not participate to the main experiment and revealed that nouns are less motor-related than verbs (see Table 1 for results). Thirty-eight pseudo-words were added to the nouns and verbs. The pseudo-words were selected to elicit the "no" response of the lexical decision task. The pseudo-word targets were orthographically and phonologically legal sequences that were created by changing one or two letters in existing words (Quemart, Casalis, \& Cole, 2011). Both the words and the pseudo-words were presented in the centre of the screen in 26 point Courier New font. 
Table 1: Median and range values (min-max) of word frequency, number of letters, number of syllables, imageability and motor-relatedness for the nouns and verbs. Given that normality and/or homogeneity assumptions were not respected for all variables, the significant differences were assessed with a non-parametric Wilcoxon test. The imageability was directly assessed by the participants at the end of the experiment. The motor-relatedness was assessed by an independent group of 37 adults (18 men, 19 women, Mean age $=40.62 \pm 11.03$ years).

$* * *$ Significant effect at $\mathrm{p}<0.001$.

\begin{tabular}{|cccc|}
\hline & Nouns $(\mathbf{n}=15)$ & Verbs $(\mathbf{n}=15)$ & Wilcoxon test \\
\hline Frequency & $31.2(1.2-307.4)$ & $26.5(1.2-305.9)$ & $\mathrm{Z}=0.74 ; \mathrm{p}=0.46$ \\
\hline Number of letters & $7(6-8)$ & $7(5-8)$ & $\mathrm{Z}=0.07 ; \mathrm{p}=0.94$ \\
\hline Number of syllables & $2(1-3)$ & $2(2-3)$ & $\mathrm{Z}=0 ; \mathrm{p}=1$ \\
\hline Imageability & $1.8(1.3-2.8)$ & $1.8(1.4-2.04)$ & $\mathrm{Z}=0.03 ; \mathrm{p}=0.98$ \\
\hline Motor relatedness & $1.2(1.05-1.6)$ & $4.9(4.6-4.9)$ & $\mathrm{Z}=3.4 ; \mathrm{p}<0.001^{* * *}$ \\
\hline
\end{tabular}

In the action decision task, the participants had to decide whether a sequence of point-light displays represented a human action. Fifteen point-light human movements (see Appendix 2 and Table 2 for a description) that represented translated or untranslated global human actions (e.g., turning cartwheels, jumping) in 2D were selected. The movements were composed of 13 points of light located on the main body joints (shoulders, elbows, wrists, hips, knees and ankles) and the head using the coordinates provided by a point-light actions corpus that is freely accessible on the following website: http://astro.temple.edu/ tshipley/mocap/dotMovie.html (see Shipley \& Brumberg, 2005 for further details). Seven to thirteen dots were simultaneously visible during the duration of the animation due to transiently hidden points. The duration of the stimuli corresponded to one 
complete cycle of each human action (Mean duration $=1683 \pm 399 \mathrm{~ms}$ ). We created fifteen scrambled point-light motions (pseudo-actions) from these biological point-light human actions. Each of these scrambled movements was made from their biological equivalent by placing each biological dot at a random location that departed from the biological equivalent display. The dynamics of each scrambled dot were identical to the human actions in accordance with the biological kinematics of human movements. Therefore, the pseudoactions followed biological kinematics but with a random position departure of each dot (i.e., with no coherent global form). The pseudo-actions had a duration that was equivalent to their biological equivalent movements. Each point-light sequence consisted of white dots (97 $\mathrm{cd} / \mathrm{m} 2, \varnothing: 0.65^{\circ}$ visual angle) that were presented on a dark background $(0.14 \mathrm{~cd} / \mathrm{m} 2)$. Using the avi file Matlab routine (http://www.mathworks. com/), each sequence was transformed to an avi movie that had a 640 x 512 pixel size and a frame rate of 40 frames/s. The stimuli were presented at the bottom of the screen, as if the movements were made on the ground (see https://bv.univ-poitiers.fr/x/X54z3h for a demonstration of each sequence display and Appendix 2 for a complete description).

\section{Procedure}

The participants sat comfortably in a dimly lit room and faced a 17" CRT computer screen (Samsung 171S, spatial resolution: 1024 x 768 pixels, sampling rate: $85 \mathrm{~Hz}$ ) that was placed on a horizontal table at a viewing distance of $50 \mathrm{~cm}$. The visual angle of the screen subtended at eye level was $26^{\circ}$ vertical $\times 32^{\circ}$ horizontal. A computer keyboard was positioned on the table close to the body so that the participants could easily provide their response during the experiment by pressing one of the keyboard keys. The participants were required to complete both the lexical decision task and the action decision task, and there was a five minute break between the two tasks (see Figure 1). The order of the tasks was counterbalanced between participants; the even numbered participants performed the lexical decision task prior to the 
action decision task, whereas the odd numbered participants performed the action decision task first. This blocked procedure was chosen to avoid the participants to make a direct relationship between the action decision task and the lexical decision task. Moreover, the block procedure was less confusing for the participants because they had not successively switch from the judgements of words to the judgements of point-light sequence and viceversa.

In the lexical decision task (see Figure 1A), the trial began with a fixation cross of $500 \mathrm{~ms}$ before the letter string appeared. The participants were required to judge whether the letter string was a word as quickly and accurately as possible. The letter strings remained visible until the participant's response was given or for a maximum of $5 \mathrm{~s}$ if a participant did not answer. Each participant was shown the 76 randomly presented letter strings (19 verbs, 19 nouns, 19 pseudo-verbs and 19 pseudo-nouns).

In the action decision task (see Figure 1B), each trial started with the presentation of a black screen for $500 \mathrm{~ms}$, after which the point-light display appeared. The thirty point-light displays (15 actions, 15 pseudo-actions) were presented in a random order. The participants were required to judge as quickly and as accurately as possible whether the point-light display represented a human action.

For both the lexical and action decision tasks, responses were given by clicking on an AZERTY computer keyboard. For the right-handed participants, the response "yes" corresponded to the letter "P," and the response "no" corresponded to the letter "A." The responses were inverted for the left-handed participants, so that the participants responded "yes" with their dominant hand.

The stimuli presentation and manual responses registration were under the control of the Eprime software (version 2.0, http://www.pstnet.com/). Accuracy and response time were recorded. 
Word imageability was estimated by the participants at the end of the experiment $(1=$ very easy, 5=impossible).

A Lexical decision task

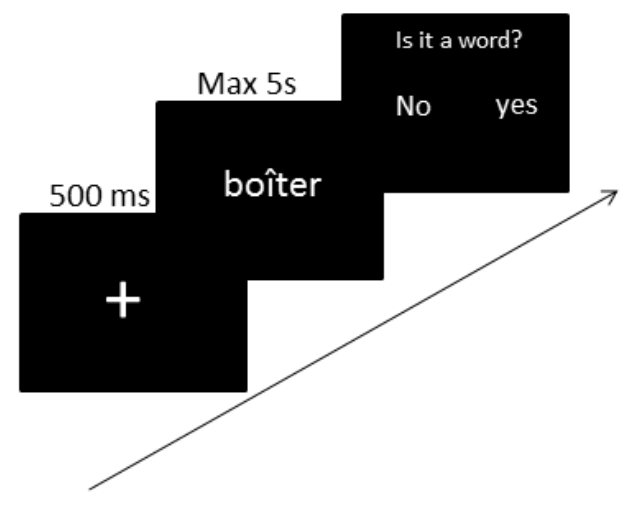

B Action decision task

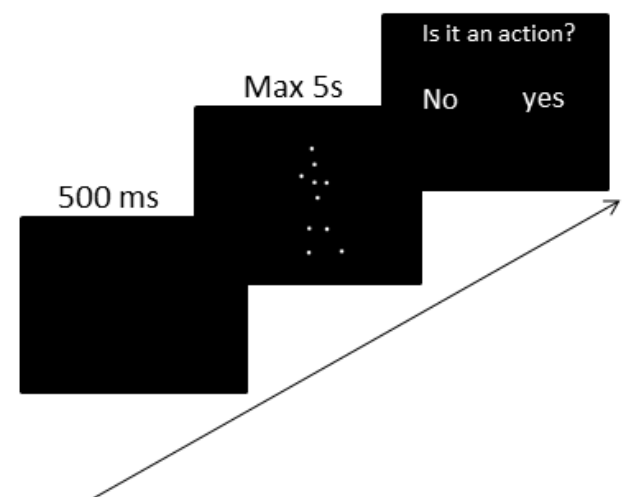

Figure 1: The procedure of the experiment for an even numbered participant; for odd numbered participants, the positions of the lexical decision task and the action decision task were counterbalanced. The arrow represents the sequence of one trial. For both tasks, as soon as the stimulus (a letter string in the lexical decision task and a point-light display in the action decision task) was presented, the participants had to decide whether it was a French word or a human action, respectively, for the lexical decision task (A) and the action decision task (B). In both tasks, the participants answered with a computer keyboard. In all cases, the response "yes" was given with the dominant hand.

\section{Data analysis}

Response accuracy and response times were assessed for each participant in each task. Moreover, to control for possible effects, we assessed word imageability for the nouns and verbs at the end of the experiment. Given the absence of normality in the data, the Wilcoxon test was used to analyse words imageability (results appear in Table 1). 
To equalize the number of stimuli analysed in each condition (nouns/verbs and point-light sequence), we decided to remove four nouns and four verbs of our material ${ }^{1}$. The choice of the four verbs and the four nouns which were removed was decided using the motorrelatedness scale (see Appendix 1). As we are particularly interested by accentuating the difference of motor-relatedness between our word's categories (i.e., between nouns and verbs), the four verbs which the lowest motor-relatedness and the four nouns which the highest motor-relatedness scores were removed (see Appendix 1). With this procedure, the number of items in the lexical decision task over the action decision task was exactly twice (i.e., 30 words vs 15 point-light sequences).

Accuracy and response times for good responses were assessed for the lexical and the action decision tasks without outliers' removal. Given that normality and/or homogeneity assumptions were not respected for all variables, we decided to perform analyses from the transformed values (arcsines transformation was applied for accuracy and logarithmic transformation was applied for response times). For facilitating the readiness of results, inverse transformations were applied to report means in text and graphs.

The lexical task was analysed with a two-way analysis of variance (ANOVA) according to the stimulus category (noun, verb) and the stimulus type (word, pseudo-word) as within-subjects factors. In the action decision task, accuracy and response times were assessed by a one-way ANOVA according to the stimulus type (action, pseudo-action). The effect sizes were computed using eta-square estimates. Eta-squared varies between 0 and 1, and is interpreted in the usual way, i.e. $0-0.1$ is a weak effect, $0.1-0.3$ is a modest effect, $0.3-0.5$ is a moderate effect and superior to 0.5 is a strong effect.

Moreover, to better assess the presence of similitude or dissociation between the action decision task and the lexical decision task, a subsequent ANOVA was made according to the

\footnotetext{
${ }^{1}$ The analysis with all items (19 nouns, 19 verbs and 15 point-light actions) gave the same principal effects and interactions concerning our hypothesizes.
} 
category (nouns, verbs, action) and the type (valid, pseudo) of stimuli as within-subjects factors and the order of tasks (language-action vs. Action-language) as a between-subjects factor. Post-hoc comparisons were made with Duncan's test. Finally, pairwise Pearson's correlations were made between the response times of each type of stimulus (i.e., nouns, pseudo-nouns, verbs, pseudo-verbs, actions and pseudo-actions). Each correlation was statistically assessed using Student's t-test.

\section{RESULTS}

\section{Correct responses}

In the lexical decision task, accuracy varied with the stimulus type $(F(1,23)=11.4 ; p<0.01$, $\left.\eta^{2}=0.33\right)$. The participants performed better for the words $(M=99.4 \%, S D=2.2 \%)$ than for the pseudo-words $(M=97.2 \%, S D=3.9 \%)$. No significant difference was observed for the stimulus category $(\mathrm{F}(1,23)=0.95 ; \mathrm{p}=0.34)$, but a significant interaction was shown between the stimulus category and the stimulus type $\left(F(1,23)=4.93 ; \mathrm{p}<0.05, \eta^{2}=0.18\right)$. The difference observed between pseudo-nouns and pseudo-verbs was higher than the difference observed between nouns and verbs.

In the action decision task, we found a significant effect of stimulus type $(F(1,23)=4.75$; $\left.\mathrm{p}<0.05, \eta^{2}=0.17\right)$. As observed for the lexical decision task, participants performed better action judgements $(M=94.4 \%, S D=7.4 \%)$ than pseudo-action judgements $(M=88.1 \%, S D$ $=11 \%)$.

\section{Response time}

In the lexical decision task, the response times varied with the stimulus category $\left(\mathrm{F}(1,23)=6.01 ; \mathrm{p}<0.05, \eta^{2}=0.21\right)$. Shorter response times were found for the nouns $(M=$ 
$735.09 \mathrm{~ms}, S D=151.4 \mathrm{~ms})$ than for the verbs $(M=759.6 \mathrm{~ms}, S D=170.7 \mathrm{~ms})$. Moreover, the words $(M=660.2 \mathrm{~ms}, S D=101.04 \mathrm{~ms})$ were recognised faster than the pseudo-words $(M=$ $\left.845.8 \mathrm{~ms}, S D=249.7 \mathrm{~ms}, \mathrm{~F}(1,23)=46.3 ; \mathrm{p}<0.001, \eta^{2}=0.66\right)$. No interaction appeared between category and type of stimulus $(\mathrm{F}(1,23)=2.5 ; \mathrm{p}=0.13)$.

In the action decision task, we obtained a significant effect of stimulus type $(F(1,23)=42.5$; $\left.\mathrm{p}<0.01, \eta^{2}=0.65\right)$. As observed for verbal stimuli, the response times were slower for the pseudo-actions $(M=1459.5 \mathrm{~ms}, S D=334.3 \mathrm{~ms})$ than for the actions $(M=1112.7 \mathrm{~ms}, S D=$ $276.7 \mathrm{~ms})$.

A

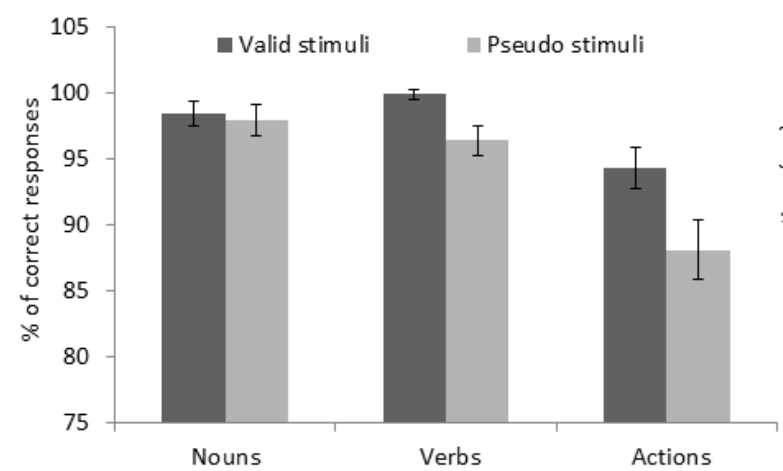

B

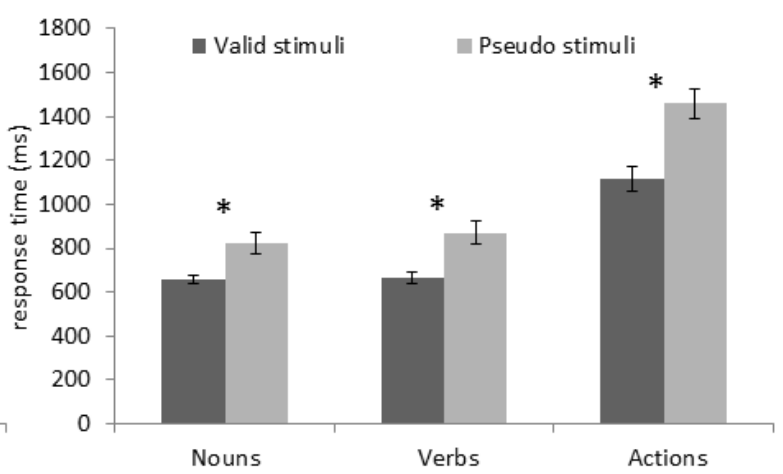

Figure 2: Mean accuracy (A) and response times (B) according to the stimulus category (nouns, verbs, action) and the stimulus type (valid, pseudo). The error bars indicate one standard error. An asterisk indicates a significant difference, with $p<0.01$. Graphs have been made from the inverse arcsine and log transformations for the accuracy and the response time respectively. 


\section{Relationship between the action and the lexical decision tasks}

\section{Global analysis}

For correct responses (Figure 2A), a significant effect of the stimulus category appeared $\left(\mathrm{F}(2,44)=24.51 ; \mathrm{p}<0.001 ; \eta^{2}=0.5\right)$. Duncan's post-hoc comparisons indicate that words judgements were easier than action judgements $(M$ words $=98.6 \%, S D=2.1 \% ;$ M action $=$ $91.5 \%, S D=6.4 \%, \mathrm{p}<0.001)$, whereas no significant difference was found between nouns and verbs $(M$ nouns $=98.3 \%, S D=3.5 \%, M$ verbs $=98.9 \%, S D=2.5 \%, \mathrm{p}=0.36)$. A significant effect of the stimulus type $\left(F(1,22)=13.9 ; p<0.001 ; \eta^{2}=0.38\right)$ was observed with more correct responses for valid stimuli $(M=98.4 \%, S D=2.9 \%)$ than for pseudo stimuli $(M=94.9 \%, S D$ $=4.6 \%)$. No significant effect appeared for the order of task $(F(1,22)=0.001 ; p=0.97)$ but we obtained a significant interaction between order and stimulus category $(F(2,44)=4.09 ; p<0.05$; $\eta^{2}=0.16$ ). No others interactions were significant (stimulus type $x$ order of task: $F(1,22)=0.10$; $p=0.75$, stimulus type $x$ stimulus category: $F(2,44)=2.58 ; p=0.08$ and stimulus type $x$ stimulus category $x$ order of task: $F(2,44)=0.36 ; p=0.7)$.

For response times (see Figure 2B), a significant effect of the stimulus category appeared $\left(\mathrm{F}(2,44)=159.2 ; \mathrm{p}<0.001 ; \eta^{2}=0.9\right)$. Duncan's post-hoc comparisons indicated that words judgements were faster than action judgements $(M$ words $=747.2 \mathrm{~ms}, S D=158.9 \mathrm{~ms} ; M$ action $=1274.4 \mathrm{~ms}, S D=277.3 \mathrm{~ms}, \mathrm{p}<0.001)$, whereas no difference was found between nouns and verbs $(M$ nouns $=735.09 \mathrm{~ms}, S D=151.4 \mathrm{~ms}, M$ verbs $=759.6 \mathrm{~ms}, S D=170.7 \mathrm{~ms}$, $\mathrm{p}=0.35)$. A significant effect of the stimulus type $\left(\mathrm{F}(1,22)=53.26 ; \mathrm{p}<0.001 ; \eta^{2}=0.7\right)$ was reported, with faster response times for valid stimuli $(M=785.7 \mathrm{~ms}, S D=138.1 \mathrm{~ms})$ than for pseudo stimuli $(M=1014.5 \mathrm{~ms}, S D=247.08 \mathrm{~ms})$. No significant effect was found for the order of task $(\mathrm{F}(1,22)=0.05 ; \mathrm{p}=0.85)$ and for interactions (stimulus category $\mathrm{x}$ order of task: $\mathrm{F}(2,44)=0.93 ; \mathrm{p}=0.40$, stimulus type $\mathrm{x}$ order of task: $\mathrm{F}(1,22)=0.65 ; \mathrm{p}=0.43$, stimulus category 
$\mathrm{x}$ stimulus type: $\mathrm{F}(2,44)=1.26 ; \mathrm{p}=0.29$, and stimulus type $\mathrm{x}$ stimulus category $\mathrm{x}$ order of task: $F(2,44)=0.60 ; p=0.55)$.

\section{Correlational analysis}

Pairwise Pearson's correlations ${ }^{2}$ were performed between the response times of all categories and types of stimuli (see Figure 3 and Table 2).

Table 2: Pearson's correlations between the response times of the various types of stimuli, where $*$ indicates $\mathrm{p}<0.05$, $* *$ indicates $\mathrm{p}<0.01$ and $* * *$ indicates $\mathrm{p}<0.001$. -----No correlations were calculated.

\begin{tabular}{|c|c|c|c|c|c|c|}
\hline & Nouns & $\begin{array}{c}\text { Pseudo } \\
\text { nouns }\end{array}$ & Verbs & $\begin{array}{c}\text { Pseudo } \\
\text { verbs }\end{array}$ & Action & $\begin{array}{l}\text { Pseudo } \\
\text { action }\end{array}$ \\
\hline Nouns & ----- & $0,63^{\star \star \star}$ & $0,77^{\star \star \star}$ & $0,68^{\star \star \star}$ & 0,32 & 0,33 \\
\hline $\begin{array}{l}\text { Pseudo } \\
\text { nouns }\end{array}$ & $0,63^{\star \star *}$ & ----- & $0,45^{\star}$ & $0,96^{* *}$ & 0,13 & $0,49^{*}$ \\
\hline Verbs & $0,77^{\star \star \star}$ & $0,45^{*}$ & ----- & $0,48^{*}$ & $0,56^{* *}$ & 0,30 \\
\hline $\begin{array}{l}\text { Pseudo } \\
\text { verbs }\end{array}$ & $0,68^{* \star *}$ & $0,96^{\star * \star}$ & $0,48^{*}$ & ----- & 0,21 & $0,59^{* * *}$ \\
\hline Action & 0,32 & 0,13 & $0,56^{* *}$ & 0,21 & ----- & $0,64^{\star * *}$ \\
\hline $\begin{array}{l}\text { Pseudo } \\
\text { action }\end{array}$ & 0,33 & $0,49^{*}$ & 0,30 & $0,59^{* * *}$ & $0,64^{\star \star *}$ & ----- \\
\hline
\end{tabular}

The individual response times for all verbal materials were positively correlated which confirmed that judgments of verbal stimuli share common mechanisms. In the same way response times for actions and pseudo-actions were also correlated. Interestingly, we observed equally positive correlations for all pseudo-material (verbal and non-verbal) which indicated that the rejection of pseudo-material (words or action) share common characteristics. Finally, we observed a specific positive correlation between the response times for verb recognition and action recognition, whereas no correlation was found between the recognition of nouns

\footnotetext{
${ }^{2}$ Note that non-parametric correlation (Spearman correlation) gave exactly the same results.
} 
and the recognition of actions. This finding indicated that the participants who were the fastest to identify the action words were also the fastest to recognise the point-light actions.
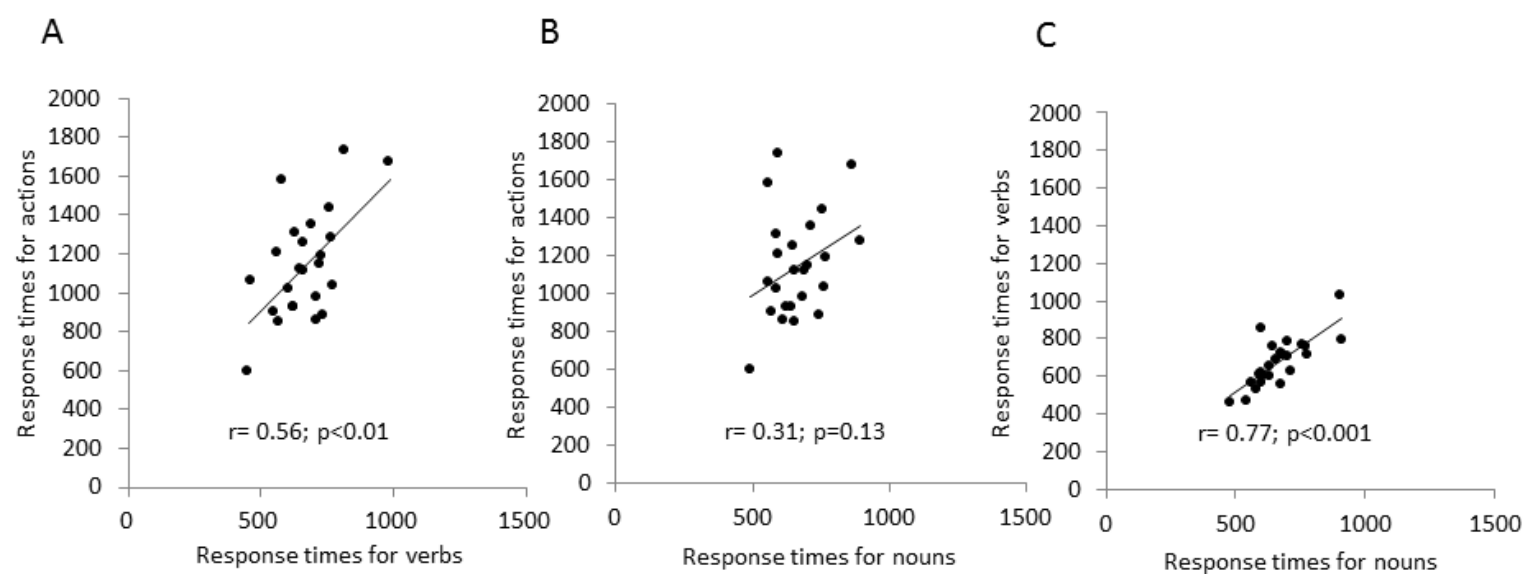

Figure 3: Pearson's correlation between individual response times A) for verbs and point-light human actions B) for nouns and point-light human actions and C) for nouns and verbs (C). All others correlations are synthetized in Table 2.

\section{DISCUSSION}

The present study aimed to determine whether point-light actions judgements and action words judgements share specific common mechanisms by comparing the behavioural performances in tasks that involve judgments of point-light actions (action decision task) and tasks that involve the judgments of letter strings (lexical decision task).

The following lines summarize the main findings. Evidence for a significant difference between the judgments of pseudo-stimuli and valid stimuli was found in the lexical and action decision tasks for both accuracy and response times. In both tasks, the performance was better when the stimuli were valid (words or point-light human action) than when they were nonvalid (pseudo-words and pseudo-actions). Concerning the lexical decision task, our results are in line with the literature in language, which shows that pseudo-words are more difficult to judge than words (Grainger \& Jacobs, 1996). In the present study, we obtained similar effects 
on both correct responses and response times for actions and pseudo-actions judgments. Interestingly, our pseudo-actions displayed the human kinematics of action but had random location departures. Consequently, as with the pseudo-words, the pseudo-actions were very similar to the valid actions. This finding suggests that judgment of pseudo-words and judgment of pseudo-actions are subject to similar constraints.

However, the present experiment indicates that action and words are treated differently in some aspects. Specifically, correct responses are lower and response times higher for actions than words. Following the known neurophysiological dissociation between occipito-temporal and occipito-parietal visual streams (Goodale, 1998), the difference between words judgements and actions judgements could be related with a pure neurophysiological dissociation where words could be preferentially treated in the ventral stream (e.g., Dehaene, Cohen, Sigman, \& Vinckier, 2005) whereas actions could be preferentially treated in the dorsal stream (e.g., Gilaie-Dotan, Bentin, Harel, Rees, \& Saygin, 2011). Moreover, we can also advance a role of the task's difficulty. Indeed, the analysis of several dynamic points required in the action decision task is more attentional consuming than the analysis of static letters required in the lexical decision task. It is also possible that participants are more familiar with words judgements than point-light actions judgements. Finally, the difference could be related with the choice of our stimuli. Actually, we decided to use 2D presentation of words and actions. However, if 2D presentation of words is classical, humans are more frequently exposed to $3 \mathrm{D}$ than $2 \mathrm{D}$ human actions in daily life. This could potentially explain the difference obtained in accuracy and response times between the words and action judgements. Nevertheless, it is unlikely that 3D action presentation would affect our results because recognition of $2 \mathrm{D}$ point-light human movements is known to be very performant in humans (Johansson, 1973) and predisposed at birth in vertebrates (Simion, Regolin, \& Bulf, 
2008; Vallortigara, Regolin, \& Marconato, 2005). This point should be assessed in future experiments.

Importantly, the correlation analysis reveals a significant relationship between the response times to the verbs and the response times to the point-light human actions. Note that no such relationship appears with nouns. To account for this relationship between action verbs and point-light judgements, we can envisage that motor activation is implicated in both tasks. Classically, the judgment of point-light actions is known to engage the motor system (BidetIldei, Chauvin, \& Coello, 2010; Casile \& Giese, 2006). For example, at the neurophysiological level, some experiments have shown that motor cerebral circuits, such as those observed in the dorsal premotor, supplementary motor, middle cingulate, somatosensory (BA3, BA2, and OP1), superior parietal, middle temporal cortex and cerebellum, are activated during the observation of human actions (mirror neuron system, e.g., Gazzola \& Keysers, 2009). At the neuropsychological level, patients who present with motor deficits have difficulties judging human actions (e.g., Chary et al., 2004). Finally, at the behavioural level, visual preferences for human movements are based on the same spatial-temporal regularities as action production (e.g., Bidet-Ildei, Méary, \& Orliaguet, 2006). Therefore, the specific correlation obtained in the present experiment between the judgments of action verbs and the judgments of point-light action is in favour to a common processing based on sensorimotor representation.

Moreover, this finding is in line with previous experiments that demonstrated that action word understanding is functionally related to the motor system (see Fadiga, Craighero, \& D'Ausilio, 2009 fo review; Fischer \& Zwaan, 2008; Jirak, Menz, Buccino, Borghi, \& Binkofski, 2010). However, as previously demonstrated in the literature (Bidet-Ildei, Sparrow, \& Coello, 2011; Khader et al., 2010; Marangolo, Cipollari, Fiori, Razzano, \& Caltagirone, 2012), in the current experiment, we show that action production is not essential to mediate the action- 
semantic relationship. Indeed, we provide evidence that a direct relationship exists between action observation and action word understanding, which suggests than motor representations are most essential than pure motor production in the action-language relationship.

Our interpretation between action recognition and action word recognition accords with the representational view of embodiment which suggests that processing of action-related words is grounded by the activation of brain's motor areas representing motor actions (Cardona et al., 2013). It is also in accordance with recent works in neuropsychology that showed that action observation is sufficient to facilitate verb recovery in aphasic patients (Marangolo et al., 2010; Marangolo et al., 2012). One explanation for this effect could be that both the judgments of action words and the visual judgments of point-light actions are based on a similar action simulation processing. This idea has been evoked in some works (Bidet-Ildei et al., 2011; Marangolo et al., 2012) and is related to the theoretical viewpoint that postulates that action words can serve to implicitly prepare the individual for future actions, similar to action observation (Barsalou, 2009; Willems, Toni, Hagoort, \& Casasanto, 2010). This is finally in line with a recent study that demonstrated that the ability to imagine action is related to the ability to recognise point-light biological motions (Miller \& Saygin, 2013). At a neurophysiological level, the superior temporal sulcus or the extrastriate body area could constitute common structures both activated for action words and action observation processing. This neurophysiological hypothesis is in agreement with studies which demonstrate specific activations in these areas when human evoked human action verbs (Lin, Lu, Fang, Han, \& Bi, 2011) or heard action sentences (de Vega et al., 2014). However, it should be assessed in future experiments.

To conclude, the present experiment demonstrates for the first time, at a functional level, the existence of similar mechanisms between action words and action observation processing. 
Similarly to pseudo-words, the judgements of pseudo-actions induce response times increase and accuracy decrease. Moreover, the correlational analysis shows a direct relationship between the treatment of action verbs and the treatment of human actions. Crucially, the ability to judge point-light human actions is specifically related with the ability to judge action verbs consistent with the existence of common processing between the two tasks. Altogether, these findings argue in favour of "embodied theory" suggesting that action observation and action-words judgements share common properties through the involvement of common motor representations (Bidet-Ildei et al., 2011; Khader et al., 2010) .

\section{ACKNOWLEDGEMENTS}

We thank Mathilde Vinel, who helped us build the stimuli and recruit the participants and Arnaud Badets for his helpful comments.

\section{REFERENCES}

Andres, M., Olivier, E., \& Badets, A. (2008). Actions, Words, and Numbers: A Motor Contribution to Semantic Processing? Current Direction in Psychological Science, 17(5), 313-317.

Aravena, P., Hurtado, E., Riveros, R., Cardona, J. F., Manes, F., \& Ibanez, A. (2010). Applauding with closed hands: neural signature of action-sentence compatibility effects. [Clinical Trial Research Support, Non-U.S. Gov't]. PloS ONE, 5(7), e11751. doi: 10.1371/journal.pone.0011751

Aziz-Zadeh, L., Wilson, S. M., Rizzolatti, G., \& Iacoboni, M. (2006). Congruent embodied representations for visually presented actions and linguistic phrases describing actions. Current Biology, 16(18), 1818-1823.

Bak, T. H., O'Donovan, D. G., Xuereb, J. H., Boniface, S., \& Hodges, J. R. (2001). Selective impairment of verb processing associated with pathological changes in Brodmann areas 44 and 45 in the motor neurone disease-dementia-aphasia syndrome. Brain, 124(Pt 1), 103-120.

Barsalou, L. W. (1999). Perceptual symbol systems. [Research Support, U.S. Gov't, NonP.H.S. Review]. Behav Brain Sci, 22(4), 577-609; discussion 610-560.

Barsalou, L. W. (2009). Simulation, situated conceptualization, and prediction. Philosophical transactions of the Royal Society of London. Series B, Biological sciences, 364(1521), 1281-1289. doi: 10.1098/rstb.2008.0319

Bidet-Ildei, C., Chauvin, A., \& Coello, Y. (2010). Observing or producing a motor action improves later perception of biological motion: Evidence for a gender effect. Acta Psychologica (Amst), 134(2), 215-224. doi: 10.1016/j.actpsy.2010.02.002 
Bidet-Ildei, C., Méary, D., \& Orliaguet, J.-P. (2006). Visual perception of elliptic movements in 7-to-11 year old children: Evidence of motor-perceptual interactions. Current psychology Letters, 2(19).

Bidet-Ildei, C., Sparrow, L., \& Coello, Y. (2011). Reading action word affects the visual perception of biological motion. Acta Psychologica (Amst), 137(3), 330-334. doi: 10.1016/j.actpsy.2011.04.001

Boulenger, V., Mechtouff, L., Thobois, S., Broussolle, E., Jeannerod, M., \& Nazir, T. A. (2008). Word processing in Parkinson's disease is impaired for action verbs but not for concrete nouns. Neuropsychologia, 46(2), 743-756. doi: 10.1016/j.neuropsychologia.2007.10.007

Boulenger, V., Roy, A. C., Paulignan, Y., Deprez, V., Jeannerod, M., \& Nazir, T. A. (2006). Cross-talk between language processes and overt motor behavior in the first $200 \mathrm{msec}$ of processing. Journal of Cognitive Neuroscience, 18(10), 1607-1615.

Cardona, J. F., Gershanik, O., Gelormini-Lezama, C., Houck, A. L., Cardona, S., Kargieman, L., \& Ibanez, A. (2013). Action-verb processing in Parkinson's disease: new pathways for motor-language coupling. [Research Support, Non-U.S. Gov't Review]. Brain Struct Funct, 218(6), 1355-1373. doi: 10.1007/s00429-013-0510-1

Casile, A., \& Giese, M. A. (2006). Nonvisual motor training influences biological motion perception. Current Biology, 16(1), 69-74.

Chary, C., Meary, D., Orliaguet, J. P., David, D., Moreaud, O., \& Kandel, S. (2004). Influence of motor disorders on the visual perception of human movements in a case of peripheral dysgraphia. Neurocase, 10(3), 223-232.

Coello, Y., \& Bidet-Ildei, C. (2012). Motor representation and language in space, object, and movement perception. In Y. Coello, \&amp; A. Bartolo (Ed.), Language and action in cognitive neuroscience. London: Psychology Press.

Cotelli, M., Borroni, B., Manenti, R., Alberici, A., Calabria, M., Agosti, C., . . Cappa, S. F. (2006). Action and object naming in frontotemporal dementia, progressive supranuclear palsy, and corticobasal degeneration. Neuropsychology, 20(5), 558-565.

de Vega, M., Leon, I., Hernandez, J. A., Valdes, M., Padron, I., \& Ferstl, E. C. (2014). Action Sentences Activate Sensory Motor Regions in the Brain Independent of Their Status of Reality. J Cogn Neurosci. doi: 10.1162/jocn_a_00559

Dehaene, S., Cohen, L., Sigman, M., \& Vinckier, F. (2005). The neural code for written words: a proposal. [Review]. Trends Cogn Sci, 9(7), 335-341. doi: 10.1016/j.tics.2005.05.004

Fadiga, L., Craighero, L., \& D'Ausilio, A. (2009). Broca's area in language, action, and music. Annals of the New York Academy of Sciences, 1169, 448-458.

Fischer, M. H., \& Zwaan, R. A. (2008). Embodied language: a review of the role of the motor system in language comprehension. Quarterly Journal of Experimental Psychology (Colchester), 61(6), 825-850.

Gazzola, V., \& Keysers, C. (2009). The observation and execution of actions share motor and somatosensory voxels in all tested subjects: single-subject analyses of unsmoothed fMRI data. Cerebral Cortex, 19(6), 1239-1255.

Gentilucci, M. (2003). Object motor representation and language. Experimental Brain Research, 153(2), 260-265.

Gilaie-Dotan, S., Bentin, S., Harel, M., Rees, G., \& Saygin, A. P. (2011). Normal form from biological motion despite impaired ventral stream function. [Research Support, N.I.H., Extramural Research Support, Non-U.S. Gov't]. Neuropsychologia, 49(5), 1033-1043. doi: 10.1016/j.neuropsychologia.2011.01.009

Glover, S., \& Dixon, P. (2002). Semantics affect the planning but not control of grasping. Experimental Brain Research, 146(3), 383-387. 
Goodale, M. A. (1998). Vision for perception and vision for action in the primate brain. [Review]. Novartis Found Symp, 218, 21-34; discussion 34-29.

Graf, M., Reitzner, B., Corves, C., Casile, A., Giese, M., \& Prinz, W. (2007). Predicting point-light actions in real-time. Neuroimage, 36 Suppl 2, T22-32.

Grainger, J., \& Jacobs, A. M. (1996). Orthographic processing in visual word recognition: a multiple read-out model. Psychol Rev, 103(3), 518-565.

Ibanez, A., Cardona, J. F., Dos Santos, Y. V., Blenkmann, A., Aravena, P., Roca, M., .. . Bekinschtein, T. (2013). Motor-language coupling: direct evidence from early Parkinson's disease and intracranial cortical recordings. [Research Support, Non-U.S. Gov't Research Support, U.S. Gov't, Non-P.H.S.]. Cortex, 49(4), 968-984. doi: 10.1016/j.cortex.2012.02.014

Jirak, D., Menz, M. M., Buccino, G., Borghi, A. M., \& Binkofski, F. (2010). Grasping language--a short story on embodiment. Consciousness and Cognition, 19(3), 711720. doi: 10.1016/j.concog.2010.06.020

Johansson, G. (1973). Visual perception of biological motion and a model for its analysis. Perception \& Psychophysics, 14, 201-211.

Khader, P. H., Jost, K., Mertens, M., Bien, S., \& Rosler, F. (2010). Neural correlates of generating visual nouns and motor verbs in a minimal phrase context. Brain Research, $1318,122-132$.

Liepelt, R., Dolk, T., \& Prinz, W. (2012). Bidirectional semantic interference between action and speech. Psychological Research, 76(4), 446-455. doi: 10.1007/s00426-011-0390-z

Lin, N., Lu, X., Fang, F., Han, Z., \& Bi, Y. (2011). Is the semantic category effect in the lateral temporal cortex due to motion property differences? [Research Support, NonU.S. Gov't]. Neuroimage, 55(4), 1853-1864. doi: 10.1016/j.neuroimage.2011.01.039

Marangolo, P., Bonifazi, S., Tomaiuolo, F., Craighero, L., Coccia, M., Altoe, G., . . . Cantagallo, A. (2010). Improving language without words: first evidence from aphasia. Neuropsychologia, 48(13), 3824-3833. doi: 10.1016/j.neuropsychologia.2010.09.025

Marangolo, P., Cipollari, S., Fiori, V., Razzano, C., \& Caltagirone, C. (2012). Walking but not barking improves verb recovery: implications for action observation treatment in aphasia rehabilitation. PLoS One, 7(6), e38610. doi: 10.1371/journal.pone.0038610

Martel, L., Bidet-Ildei, C., \& Coello, Y. (2011). Anticipating the terminal position of an observed action: Effect of kinematic, structural, and identity information. Visual Cognition, 19(6), 785-798.

Miller, L. E., \& Saygin, A. P. (2013). Individual differences in the perception of biological motion: links to social cognition and motor imagery. Cognition, 128(2), 140-148. doi: 10.1016/j.cognition.2013.03.013

Nazir, T. A., Boulenger, V., Roy, A., Silber, B., Jeannerod, M., \& Paulignan, Y. (2008). Language-induced motor perturbations during the execution of a reaching movement. Q J Exp Psychol (Colchester), 61(6), 933-943.

New, B., Pallier, C., Ferrand, L., \& Matos, R. (2001). Une base de données lexicales du français contemporain sur internet: LEXIQUE. L'Année psychologique, 101, 447-462. http://www.lexique.org.

Peran, P., Demonet, J. F., Pernet, C., \& Cardebat, D. (2004). Verb and noun generation tasks in Huntington's disease. Movement Disorder, 19(5), 565-571.

Peran, P., Rascol, O., Demonet, J. F., Celsis, P., Nespoulous, J. L., Dubois, B., \& Cardebat, D. (2003). Deficit of verb generation in nondemented patients with Parkinson's disease. Mov Disord, 18(2), 150-156. 
Pulvermüller, F. (2013). How neurons make meaning: brain mechanisms for embodied and abstract-symbolic semantics. Trends in Cognitive Sciences, 17(9), 458-470. doi: 10.1016/j.tics.2013.06.004

Quemart, P., Casalis, S., \& Cole, P. (2011). The role of form and meaning in the processing of written morphology: A priming study in French developing readers. [Research Support, Non-U.S. Gov't]. Journal of Experiemantal Child Psychology, 109(4), 478496. doi: 10.1016/j.jecp.2011.02.008

Shipley, T. F., \& Brumberg, J. S. (2005). Markerless motion-capture for point-light displays. Available at http://astro.temple.edu/ tshipley/mocap/MarkerlessMoCap.pdf.

Simion, F., Regolin, L., \& Bulf, H. (2008). A predisposition for biological motion in the newborn baby. Proceedings of the National Academy of Sciences, 105(2), 809-813.

Springer, A., Huttenlocher, A., \& Prinz, W. (2012). Language-induced modulation during the prediction of others' actions. Psychological Research. doi: 10.1007/s00426-012-04116

Springer, A., \& Prinz, W. (2010). Action semantics modulate action prediction. Quarterly Journal of Experimental Psychology (Colchester), 1-18.

Vallortigara, G., Regolin, L., \& Marconato, F. (2005). Visually inexperienced chicks exhibit spontaneous preference for biological motion patterns. PLoS Biology, 3(7), e208.

Willems, R. M., Toni, I., Hagoort, P., \& Casasanto, D. (2010). Neural dissociations between action verb understanding and motor imagery. Journal of Cognitive Neuroscience, 22(10), 2387-2400. doi: 10.1162/jocn.2009.21386

Wilson, M. (2002). Six views of embodied cognition. [Review]. Psychon Bull Rev, 9(4), 625636. 
Appendix 1: Detailed list of the words used in the lexical decision task. English translation of each word appeared in brackets. The imageability was directly assessed by the participants at the end of the experiment. The motor-relatedness was assessed by an independent group of 37 adults (18 men, 19 women, Mean age=40.62 \pm 11.03 years). On the basis of motorrelatedness analysis, words written in bold italics have been removed of the final analysis to equalize the number of words and actions used. As we are particularly interested by accentuating the difference of motor-relatedness between word categories (i.e., between nouns and verbs), we removed the four verbs with the lowest motor-relatedness and the four nouns with the highest motor-relatedness scores.

\begin{tabular}{|c|c|c|c|c|c|c|c|}
\hline Word & $\begin{array}{c}\text { Pseudo- } \\
\text { word }\end{array}$ & Type & Frequency & $\begin{array}{l}\text { Nb of } \\
\text { letters }\end{array}$ & $\begin{array}{c}\text { Nb of } \\
\text { syllabes }\end{array}$ & Imageability & Motor-relateness \\
\hline $\begin{array}{c}\text { Araignée } \\
\text { (spider) }\end{array}$ & agnairée & Noun & 18.20 & 8 & 3 & 1.38 & 1.19 \\
\hline $\begin{array}{l}\begin{array}{l}\text { Armée } \\
(\text { Army })\end{array} \\
\end{array}$ & émare & Noun & 101.07 & 5 & 2 & 2.13 & 1.70 \\
\hline $\begin{array}{c}\text { Bâtiment } \\
\text { (building) }\end{array}$ & bamitent & Noun & 27.58 & 8 & 3 & 1.8 & 1.19 \\
\hline $\begin{array}{c}\text { Bottine } \\
\text { (boot) }\end{array}$ & bittone & Noun & 2.27 & 7 & 2 & 2.08 & 1.49 \\
\hline $\begin{array}{c}\begin{array}{c}\text { Bureau } \\
\text { (desk) }\end{array} \\
\end{array}$ & rubeau & Noun & 167.13 & 6 & 2 & 1.54 & 1.27 \\
\hline $\begin{array}{c}\begin{array}{c}\text { Casque } \\
\text { (helmet) }\end{array} \\
\end{array}$ & quesca & Noun & 15.42 & 6 & 1 & 1.67 & 1.27 \\
\hline $\begin{array}{c}\text { Citron } \\
\text { (lemon) }\end{array}$ & cotrin & Noun & 10.92 & 6 & 2 & 1.29 & 1.11 \\
\hline $\begin{array}{c}\text { Cochon } \\
\text { (pig) }\end{array}$ & chocon & Noun & 31.18 & 6 & 2 & 1.29 & 1.14 \\
\hline $\begin{array}{l}\begin{array}{l}\text { Copain } \\
\text { (friend) }\end{array} \\
\end{array}$ & capoin & Noun & 158.62 & 6 & 2 & 2.13 & 1.16 \\
\hline $\begin{array}{c}\text { Épée } \\
\text { (sword) }\end{array}$ & éphée & Noun & 32.81 & 5 & 2 & 1.42 & 1.86 \\
\hline $\begin{array}{l}\text { Étudiant } \\
\text { (student) }\end{array}$ & éduitant & Noun & 38.07 & 8 & 3 & 2.21 & 1.38 \\
\hline $\begin{array}{l}\begin{array}{l}\text { Guitare } \\
\text { (guitar) }\end{array} \\
\end{array}$ & gaiture & Noun & 13.86 & 8 & 2 & 1.38 & 1.78 \\
\hline $\begin{array}{c}\begin{array}{c}\text { Haricot } \\
\text { (bean) }\end{array} \\
\end{array}$ & hiracot & Noun & 8.85 & 7 & 3 & 1.46 & 1.05 \\
\hline $\begin{array}{c}\text { Madame } \\
(\mathrm{Mrs})\end{array}$ & mamade & Noun & 307.36 & 6 & 2 & 2.04 & 1.11 \\
\hline $\begin{array}{c}\text { Magasin } \\
\text { (shop) }\end{array}$ & gamasin & Noun & 60.62 & 7 & 3 & 1.92 & 1.16 \\
\hline $\begin{array}{l}\text { Million } \\
\text { (million) }\end{array}$ & mililon & Noun & 124.70 & 7 & 2 & 2.83 & 1.05 \\
\hline $\begin{array}{c}\text { Piscine } \\
\text { (swimming } \\
\text {-pool) }\end{array}$ & pisucine & Noun & 23.62 & 7 & 2 & 1.33 & 1.70 \\
\hline Sablier & sibaler & Noun & 1.18 & 7 & 3 & 1.83 & 1.57 \\
\hline
\end{tabular}




\begin{tabular}{|c|c|c|c|c|c|c|c|}
\hline (timer) & & & & & & & \\
\hline $\begin{array}{l}\begin{array}{l}\text { Sorcier } \\
\text { (witch) }\end{array} \\
\end{array}$ & socrier & Noun & 54.09 & 7 & 2 & 2.42 & 1.19 \\
\hline $\begin{array}{c}\text { Balancer } \\
\text { (swing) }\end{array}$ & banlacer & Verb & 40.12 & 8 & 3 & 1.96 & 4.54 \\
\hline $\begin{array}{l}\begin{array}{l}\text { Balayer } \\
\text { (sweep) }\end{array} \\
\end{array}$ & labayer & Verb & 12.17 & 7 & 3 & 1.58 & 4.92 \\
\hline $\begin{array}{l}\text { Boiter } \\
\text { (limp) }\end{array}$ & Bioter & Verb & 15.43 & 6 & 2 & 2.21 & 4.1 \\
\hline $\begin{array}{c}\text { Caresser } \\
\text { (stroke) }\end{array}$ & cerasser & Verb & 15.69 & 8 & 3 & 1.88 & 4.86 \\
\hline $\begin{array}{l}\text { Couper } \\
\text { (cut off) }\end{array}$ & Copuer & Verb & 155.82 & 6 & 2 & 1.79 & 4.95 \\
\hline $\begin{array}{c}\text { Creuser } \\
\text { (dig) }\end{array}$ & Ceruser & Verb & 25.11 & 7 & 2 & 1.96 & 4.96 \\
\hline $\begin{array}{c}\text { Cueillir } \\
\text { (pick) }\end{array}$ & Ceilluir & Verb & 13.84 & 8 & 2 & 1.88 & 4.89 \\
\hline $\begin{array}{c}\begin{array}{c}\text { Déchirer } \\
\text { (tear) }\end{array} \\
\end{array}$ & Dichérer & Verb & 26.46 & 8 & 3 & 1.83 & 4.86 \\
\hline $\begin{array}{l}\text { Écrire } \\
\text { (write) }\end{array}$ & Ercire & Verb & 305.92 & 6 & 2 & 1.71 & 4.84 \\
\hline $\begin{array}{c}\text { Fumer } \\
\text { (smoke) }\end{array}$ & mufer & Verb & 98.49 & 5 & 2 & 1.5 & 4.11 \\
\hline $\begin{array}{l}\begin{array}{l}\text { Lâcher } \\
\text { (drop) }\end{array} \\
\end{array}$ & lancher & Verb & 171.08 & 6 & 2 & 2.04 & 4.57 \\
\hline $\begin{array}{l}\text { Nager } \\
\text { (swim) }\end{array}$ & ganer & Verb & 30.36 & 5 & 2 & 1.38 & 4.86 \\
\hline $\begin{array}{l}\begin{array}{l}\text { Peigner } \\
\text { (comb) }\end{array} \\
\end{array}$ & pengier & Verb & 2.25 & 7 & 2 & 1.79 & 4.89 \\
\hline $\begin{array}{l}\text { Pincer } \\
\text { (pinch) }\end{array}$ & pinocer & Verb & 10.84 & 6 & 2 & 1.80 & 4.92 \\
\hline $\begin{array}{l}\text { Pivoter } \\
\text { (rotate) }\end{array}$ & Poviter & Verb & 1.19 & 7 & 3 & 1.96 & 4.78 \\
\hline $\begin{array}{c}\text { Pousser } \\
\text { (push) }\end{array}$ & pusoser & Verb & 125.61 & 7 & 2 & 1.58 & 4.84 \\
\hline $\begin{array}{c}\text { Reculer } \\
\text { (Step back) }\end{array}$ & ruceler & Verb & 52.15 & 7 & 3 & 1.63 & 4.84 \\
\hline \begin{tabular}{|l|}
$\begin{array}{l}\text { Sourire } \\
(\text { smile })\end{array}$ \\
\end{tabular} & Soruire & Verb & 53.97 & 7 & 2 & 1.42 & 3.94 \\
\hline $\begin{array}{l}\text { Verser } \\
\text { (spill) }\end{array}$ & Vreser & Verb & 31.20 & 6 & 2 & 1.96 & 4.84 \\
\hline
\end{tabular}


Appendix 2: Detailed list of human actions used in the experiment.

\begin{tabular}{|c|c|c|c|}
\hline Action & Description & View & $\begin{array}{c}\text { Time } \\
\text { duration }\end{array}$ \\
\hline $\begin{array}{c}\text { Baseball } \\
\text { throw }\end{array}$ & A man carrying a baseball and throwing it leftward & Profile & $550 \mathrm{~ms}$ \\
\hline Cartwheel & A man doing a cartwheel to the left & $\begin{array}{c}\text { Three } \\
\text { quarter }\end{array}$ & $1800 \mathrm{~ms}$ \\
\hline Crawl & A man crawling & Profile & $1650 \mathrm{~ms}$ \\
\hline Dancing & A man dancing salsa & $\begin{array}{c}\text { Three } \\
\text { quarters }\end{array}$ & $2300 \mathrm{~ms}$ \\
\hline Iatatex & A man giving a kick forward & $\begin{array}{l}\text { Three- } \\
\text { quarters }\end{array}$ & $1525 \mathrm{~ms}$ \\
\hline $\begin{array}{c}\text { Jumping } \\
\text { jack }\end{array}$ & A man jumping with his arms and legs opening and closing & Front & $1475 \mathrm{~ms}$ \\
\hline $\begin{array}{c}\begin{array}{c}\text { Karate } \\
\text { kick }\end{array} \\
\end{array}$ & A man giving a kick with a translation to the left & $\begin{array}{c}\text { Three } \\
\text { quarter }\end{array}$ & $1450 \mathrm{~ms}$ \\
\hline Pick up & A man bending down to pick something up & $\begin{array}{c}\text { Three } \\
\text { quarters }\end{array}$ & $1800 \mathrm{~ms}$ \\
\hline Place kick & A man kicking a ball with a rightward translation & $\begin{array}{c}\text { Three } \\
\text { quarters }\end{array}$ & $1900 \mathrm{~ms}$ \\
\hline$\overline{\text { Push }}$ & A man pushing something to his left & Front & $1725 \mathrm{~ms}$ \\
\hline Push up & A man doing push-ups & Profile & $2075 \mathrm{~ms}$ \\
\hline Run & A man running (leftward direction) as if on a treadmill & Profile & $1800 \mathrm{~ms}$ \\
\hline Sit down & A man beginning to sit & $\begin{array}{c}\text { Three } \\
\text { quarters }\end{array}$ & $1375 \mathrm{~ms}$ \\
\hline Twist & A man doing a twist & Front & $1875 \mathrm{~ms}$ \\
\hline Walk & A man walking (leftward direction) as if on a treadmill & Profile & $1950 \mathrm{~ms}$ \\
\hline
\end{tabular}

